\title{
ResearchArticle
}

\section{Contribution of folk medicines in rural health care in Kanpur and adjacents areas}

Nikhil Agnihotri

\begin{abstract}
SUMMARY
India has great heritage knowledge of medicinal utility of plants since ancient times. In a vast country like India folk medicines play very important and vital role in primary health care conservation in rural life. The medicinal utility of these plants is not decreased after thousands of the year. A lot of plant species occurs as self grown conditions which are known as weeds are being used by peoples for treatment of various diseases. Present study based on utility of self grown plants or weeds as house hold, folk or ethno medicine in and around the Kanpur. In the study there are 84 self grown weeds are identified and analyzed with their local names, botanical names, families, habit and habitats, conservation methods and medicinal utility against various diseases. Most of the plants are useful in more than one disease and easily available through the year. By conserving these plants we can make treatment cheaper non-reactive, safer and easily accessible to every one. It is also observed that poor or less literate persons have more knowledge than well literate and higher income group of persons. Present study highlighted new opportunities about the self grown medicinal plants relating conservation, protection, documentation and sustainable rural development.
\end{abstract}

Key Words : Self grown, Medicinal, Ethno medicinal, Folk medicine

How to cite this article : Agnihotri, Nikhil (2018). Contribution of folk medicines in rural health care in Kanpur and adjacents areas. Internat. J. Plant Sci., 13 (2): 256-264, DOI: 10.15740/HAS/IJPS/13.2/256-264, Copyright@ 2018: Hind Agri-Horticultural Society.

Article chronicle : Received : 13.12.2017; Revised : 18.06.2018; Accepted : 29.06.2018

\footnotetext{
$\longrightarrow \quad$ AUTHOR FOR CORRESPONDENCE

Nikhil Agnihotri, Department of Botany, S.K.J.D. P.G. College,

Mangalpur, Kanpur Dehat (Kanpur) India

Email : nikhil.azolla@gmail.com
} 